\title{
ADHERING AGILE METHODOLOGY IN COVID-19
}

\author{
ANJALI SINGHAL
}

Inderprastha Engineering College, Ghaziabad, India

\begin{abstract}
An approach followed to design and develop any software has an important role in determining the reliability and quality of the final Software product. So proper guidelines are required to develop a software. There are different models, that are being followed by different companies as per their requirements. Among all, Agile methodologies are most popular because of its flexibility and adaptability. But that is possible because this model involves continuous customer interaction. There are short development cycles. After which there is interaction between the stakeholders. If there is an issue or change, that is incorporated in the next cycle. The Covid-19 pandemic has a destructive effect on the socioeconomic state. This has resulted in the closure of many companies. The companies which change strategies and adapt to the current situation survived. Agility assists companies in making new changes and adapting their business in this pandemic. This paper outlines on how adhering to agile methodology assist software companies in developing software and also helped government, business organization and their supply chain in coping up with the Covid-19 pandemic.

KEYWORDS: COVID-19, Agility \& Uncertainty
\end{abstract}

Received: Jun 14, 2021; Accepted: Jul 04, 2021; Published: Jul 15, 2021; Paper Id: IJCSEITRDEC20216

\section{INTRODUCTION}

In the present situation of the COVID-19 pandemic, agile methodology is becoming more operational because of its dynamic capabilities. Today when there are risks and uncertainty, the flexibility of Agile is making it more favorable. The major factors, that are targeted through this includes opportunity intelligence in the present risks, the capability of employees and flexibility in IT.

In Agile Manifesto, the main stress is that if there is any requirement change, that can not be avoided at any interval of time. There is incremental development through continuous customer feedback in regular intervals of time. This helps in removing the risk and uncertainty as this model focuses on customer collaboration and responding to change. The customer does express all the requirements in one stretch, so this easily incorporates uncertainty or change at any stage.

A survey shows that large scale adoption of Agile methodologies in the present scenario. In starting months of 2020, when the pandemic was spreading, software companies were exposed to uncertainty. None of the stakeholders (customer as well as developer) was in situation to predict the response of the product in the beginning. They tried to adjust their work to the new scenario to avoid risks. They tried to adapt their system as per agile practices. Companies rearrange their activities and allocate resources to reduce risks. At every iteration or sprint, the stakeholders review the work jointly. They prioritize and select those features, that can lead to risk if not handled properly. In other traditional models (like waterfall model), the decision regarding features cannot be reversed in the next stage. But during the pandemic, as there is uncertainty regarding the acceptance of idea or product. Agile methodology can incorporate changes at any stage to reduce risk. 


\section{FACTORS WHICH HELPS IN ADHERING TO AGILE METHODOLOGY}

The current situation is unstable and uncertain from financial and economic prospects. This encourages the importance of agile methodology. There is evidence that all though on a smaller scale, companies started adopting agile methodologies. The companies who adopted agile were more successful as compared to companies who didn't adopt.

The reasons behind this are as follows:

- Rapid Decision Making: The re-alignment of decision as per the changes in the requirement. It is very necessary so as to align development and requirement. As in agile methodology, there is rapid discussion and decision making after every short cycle, companies were able to sustain successfully in the pandemic by making fast decisions. They were able to identify the critical process and were able to develop back-up plans to sustain in crisis. They worked like war games with the mindset to adapt to the crisis. This helped them in attaining clarity and take decisions before time.

- Flexibility in designing and developing: As due to pandemic, developers, as well as infrastructure for developing, was made accessible through different ( even through remote places) were required. They can easily embed new technologies in ongoing work.

- Capability of programmers: Agile methodology stress on domain knowledge and skill of the team members. This stresses on programmer's skill and motivation. The uncertainty in the situation requires programmer's flexibility to adapt to dynamic changes. This includes making employees feel empowered. They rather than depending on rigid processes, use their own skills acting as visionaries and architects.

\section{FACTORS WHICH RESTRICT IN ADHERING TO AGILE METHODOLOGY}

Due to the Covid-19 pandemic, the concept of Work From Home is being implemented by most of the software companies for the past year. So now the programmers are working from different locales. But as Agile methodology requires periodic meetings, companies were facing problems in adapting to this concept. There are some barriers in this methodology. These are as follows:

- Team Silos: Agility requires working in cross-collaboration. This requires sharing of knowledge of experts among team members. But as during the pandemic, team members were working from distant locations act as a barrier. Well-established relationship could not be established, they are not able to co-develop ideas, and test together. So Cross collaboration is required among team members working from different locations.

- Ambiguity in goal: In the current situation of the pandemic, everything is uncertain. Setting up a fixed goal is very difficult. Team members are at different locations, in this asking them to operate at a particular speed to achieve a shared goal becomes difficult. Understanding shared goals and not the individual part is very important to work effectively.

- Balancing stability and new changes: Agility is full of experiments and their collaboration. That means Agility requires support for risk tolerance. But new ideas require discussion among team members to evaluate that. Incorporation of new changes in the development and along with that stability is very much important.

\section{APPLICATION OF AGILE METHODOLOGY ON SYSTEMS OTHER THAN SOFTWARE}




\section{DEVELOPMENT CYCLE}

Key aspect to agile methodology is change. Today when the is uncertainty due to Covid -19 , the government is also following this. This is quite reactive way of working, with the aim is to cope with the current environment. Agility enhances the capacity of the government to deal with change along with protecting society from the current instability. The government in various countries use this to deal with risks associated with the spread of the virus in society.

Agility helped companies and their supply chain in sustaining and meeting uncertain demands during this period. The main aspect of Agile methodology is its flexibility and decision making according to the new requirement. The relevant data of various supply chain networks enable the industry to make decision as per the changes in the business environment. During this unpredicted time availability of data regarding demand, capacity, production, supply and skill management across various levels helps in responding better. The integration of all information helps the system's agile methodology to make a correct decision and step forward.

Some of the domains where Government apply where agility is used are:

- Availability of funds to keep economy on track

- Availability of essential services

- Conducting testing

- Availability of hospitals and medical services

- Availability of drugs and oxygen etc

- Applying small lockdowns.

The main concepts of Agile that are time, central decision making and flexibility were used to control all the above domains. The key to success of Agility are working in integrated team, stepwise series of small improvements after gaining feedbacks from society and improving further. Flexibility helps an organization to modify their range of services and products. They are able to promote innovation. As cycles of agile are small, this helps the system to review and respond with better services.i

The main focus was on changes in the environment and their response. Emphasis is on speedy change to work with the right solution. Agile methodology helps the government to work in short-short time span and review and decide for further. Initially, it was felt very conflicting concept for government to adapt, but it was later found to be more beneficial in environment full of change and uncertainty. This is because agile stresses quick decision making and responding accordingly.

\section{CONCLUSIONS}

Different organizations responded differently when Covid 19 hit the world. Agile concept played a vital role. This ensures working with those practices and methods, that can give quick responses. The motive was that, the product or solution to a program should be released quickly, so that that can be assessed early and improvements can be done accordingly. This adaptive method played an important role in the period of uncertainty due to Covid 19. this facilitates quick and timely response to the changes in customer needs and environmental changes. Earlier this methodology had been adopted for developing software products, but gradually other services have also started adopting this methodology. 


\section{REFERENCES}

1. Krzysztof Marek, Ewelina Wińska Włodzimierz Dąrowski: The State of Agile Software Development Teams During the Covid19 Pandemic, Lean and Agile Software Development, Vol. 408, 2021

2. P. Ralph, S. Baltes, G. Adisaputri, R.Torkar, V. Kovalenko, M. Kalinowski, N. Novielli, S. Yoo,

3. X. Devroey, X. Tan, M. Zhou, B. Turhan, R. Hoda, H. Hata, G. Robles, A. Milani Fard, and

4. R. Alkadhi: Pandemic programming how covid-19 affects software developers and how their

5. organizations can help, Empirical Software Engineering, 2020.

6. Dongthi Thao Nguyen \& Kieuthi Thu Chung, "New Trends in Technology Application in Education and Capacities of Universities Lecturers during the Covid-19 Pandemic”, International Journal of Mechanical and Production Engineering Research and Development (IJMPERD), Vol. 10, Issue 3, pp, 1709-1714

7. J. Pantiuchina, M. Mondini, D. Khanna, X. Wang, and P. Abrahamsson: Are software startups applying agile practices? the state of the practice from a large survey, ICASD, Springer, 2017, pp. 167-183.

8. Sirisha Deepthi Sornapudi \& Meenu Srivastava, “Face Mask For Covid-19: A Social Responsibility”, International Journal of Agricultural Science and Research (IJASR), Vol. 10, Issue 3, pp, 1-6

9. S. M. Sutton: The role of process in software start-up, IEEE software, vol. 17, no. 4, pp. 33-39, 2000.

10. Ehab M. Almetwally \& Gamal M. Ibrahim, "Discrete Alpha Power Inverse Lomax Distribution with Application of COVID19 Data”, International Journal of Applied Mathematics \& Statistical Sciences (IJAMSS), Vol. 9, Issue 6, pp; 11-22

11. M. Marinho, S. Sampaio, T. Lima, and H. Moura: A systematic review of uncertainties in software project management, International Journal of Software Engineering \& Applications, vol. 5, pp. 23-32, 2014.

12. Woodcock H: The Agile Manifesto Reworked for Systems Engineering, INCOSE UK, ASEC Conf., 2012.

13. Mufutau Akanmu Popoola, Shittu Muili Olawale \& Hamzart Kabirat Abosede, "Effect of COVID-19 Outbreak on Socioeconomic Development in Nigeria”, International Journal of General Medicine and Pharmacy (IJGMP), Vol. 9, Issue 5, pp; $29-36$

14. Douglas BP: Agile Systems Engineering.Morgan Kaufman; 2015. Agile Manifesto. Agile Manifesto. http://agilemanifesto.org/.

15. Roser M, Ritchie H, Ortiz-Ospina E, Hasell J.:Statistics and Research-Coronavirus Pandemic (COVID-19). Our World in Data, 2020.

16. INCOSE: Agile systems engineering. www.incose.org/Chapters Groups/Working Groups/transformational/agile-systems-se. July 21, 2020.

17. Haushofer J, Metcal JE.: Combining Behavioral Economics and Infectious Disease Epidemiology to Mitigate theCOVID-19 Princeton University; 2020.

18. McKibbin, W.J., Roshen, F.: The Global Macroeconomic Impacts of COVID-19: Seven Scenarios. CAMA,2020

19. Dingsoyr T, Nerur S, Balijepally V, Moe NB: A decade of agile methodologies: towards explaining agile software development. J Syst Softw. 2012

20. Robinson, P.T.: Communication network in an agile distributed software development team. In: 14th International Conference on Global Software Engineering, pp. 100-104. IEEE,2019 
21. Harzing A-W.: The Publish or Perish Book. Melbourne: Tarma Software Research Pty Ltd; 2010.

22. CSSE. COVID-19 Dashboard by the Center for Systems Science and Engineering (CSSE) at Johns Hopkins. Center for Systems Science and Engineering (CSSE), Johns Hopkins University. 2020.

23. Batra, D., Xia, W., \& Rathor, S.:Agility facilitators for contemporary software development. Journal of Database Management (JDM), 2016

24. Sharma, S., Hasteer, N.: A comprehensive study on state of Scrum development In: International Conference on Computing, Communication and Automation (ICCCA), pp. 867-872. IEEE, 2016

25. Conboy, K.: Agility from first principles: Reconstructing the concept of agility in information systems development. Information Systems Research, 2009

26. Hartmann, D., Dymond, R.: Appropriate agile measurement: using metrics and diagnostics to deliver business value. In: AGILE, pp. 126-131. IEEE (2006)

27. Kurnia, R., Ridi F., Sunu W.: Software metrics classification for agile scrum process: a literature review .International Seminar on Research of Information Technology and Intelligent Systems, pp. 174-179. IEEE (2018)

28. Robinson, P.T.: Communication network in an agile distributed software development team. In: ACM/IEEE 14th International Conference on Global Software Engineering, pp. 100-104. IEEE 2019

29. Paasivaara, M., Behm, B., Lassenius, C., Hallikainen, M.: Large-scale agile transformation at Ericsson: a case study. Empirical Softw. Eng.2018. 
